\title{
The effect of externally attached archival data loggers on the short-term dispersal behaviour and migration speed of European eel (Anguilla anguilla L.)
}

Pieterjan Verhelst ${ }^{1,2^{*}} \mathbb{D}$, Kim Aarestrup ${ }^{3}$, Gustav Hellström ${ }^{4}$, Niels Jepsen ${ }^{3}$, Anders Koed ${ }^{3}$, Jan Reubens ${ }^{5}$, Niklas Sjöberg ${ }^{5}$, Jon Christian Svendsen ${ }^{3}$ and Martin Lykke Kristensen ${ }^{3}$

\begin{abstract}
Background: Externally attached archival data logging tags are increasingly used to unravel migration routes of fish species at sea. Due to the relatively large size of the tags, their application on seaward migrating anguillid eels often forms a challenge in terms of feasibility and impact on the eel's swimming performance. In this study, we investigated the impact of externally attached pop-up data storage tags (PDSTs) on the departure direction, time spent at the release location and ground speed of European eels (Anguilla anguilla).

Results: We tagged 66 eels with internal acoustic transmitters of which half of the eels were additionally tagged with externally attached PDSTs. A network of acoustic receivers allowed us to analyse if the dispersal behaviour (i.e. residence time and departure direction) from the release site differed between eels tagged with and without the PDSTs. In addition, we tracked the eels for ca. $83 \mathrm{~km}$ in the marine environment and determined their migration speed. The results showed no differences between eels tagged with or without external PDSTs in respect of the external tagging effect on residence time $(n=60)$, departure direction at the release site $(n=60)$ or on the migration speed $(n=20)$.

Conclusions: We conclude that the impact of the PDSTs is minimal on these metrics for at least the first part of the marine migration. While these field-based findings suggest that anguillid eels may be largely unaffected by the applied PDSTs, we recognize that more research is needed in both the field and the laboratory to study the impact of PDSTs and externally attached tags in general on fish swimming performance and energy expenditure. This can help interpret the results from the field, but also aid developing more hydrodynamic tag shapes or improved attachment methods.
\end{abstract}

Keywords: Anguilla, Migration, Tagging effect, External tagging, Data logger, Acoustic, Archival, Data storage tags

\section{Background}

The application of externally attached archival tags to track aquatic animals has increased substantially over the past decades, mainly due to technological

*Correspondence: pieterjan.verhelst@inbo.be

${ }^{1}$ Aquatic Management, Research Institute for Nature and Forest (INBO), Havenlaan 88, Bus 73, 1000 Brussels, Belgium

Full list of author information is available at the end of the article improvements and their potential for revealing behaviour nearly impossible to study with other methods [1]. Archival tags record and store environmental data such as temperature, pressure (i.e. depth) and light. Based on these data, large-scale movement trajectories of an aquatic animal can be reconstructed (e.g. Pedersen et al. [2], Wright et al. [3]). The data can be obtained either by active transmission of data (e.g. pop-up satellite archival tags (PSATs)) or by the tag being physically original author(s) and the source, provide a link to the Creative Commons licence, and indicate if changes were made. The images or other third party material in this article are included in the article's Creative Commons licence, unless indicated otherwise in a credit line to the material. If material is not included in the article's Creative Commons licence and your intended use is not permitted by statutory regulation or exceeds the permitted use, you will need to obtain permission directly from the copyright holder. To view a copy of this licence, visit http://creativecommons.org/licenses/by/4.0/. The Creative Commons Public Domain Dedication waiver (http://creativeco mmons.org/publicdomain/zero/1.0/) applies to the data made available in this article, unless otherwise stated in a credit line to the data. 
retrieved, so the data can be downloaded from the device (data storage tags (DST)). DSTs have in recent years often been made floating to increase the chance of recovery and come with or without a pop-up mechanism (i.e. pop-up data storage tags (PDSTs)). These techniques are especially useful in marine systems where it is often impossible to cover large areas with receivers such as acoustic telemetry, as they have a limited detection range.

An important limitation of archival tags is their size. DSTs can be small (e.g. G5 standard tag, weighing only $2.7 \mathrm{~g}$ in air, measure $31 \mathrm{~mm}$ in length and $8 \mathrm{~mm}$ diameter (CEFAS Technology Ltd, UK). However, adding flotation and/or a pop-up mechanisms substantially increases the size. A G5 PDST weighs $32 \mathrm{~g}$ in air and measure $61 \mathrm{~mm}$ in length and $15 \mathrm{~mm}$ in diameter (CEFAS Technology Ltd, UK). The smallest PSAT on the market weighs $46 \mathrm{~g}$ in air, measures $122 \mathrm{~mm}$ in length and $33 \mathrm{~mm}$ in diameter (X-Tag, Microwave Telemetry Inc., USA). This restricts both tag types to larger animals and also raises the question about potential tag effect on smaller animals [1]. Despite their sizes, floating archival tags are applied to relatively small fish as well (less than $2 \mathrm{~kg}$ ). Semelparous, catadromous anguillid eels are frequently tagged with floating archival tags to map their migration routes and unravel unknown spawning locations [4-9]. Attaching floating archival tags externally to these relatively small animals may affect their migration speed due to hydrodynamic interferences by drag. Hence, various laboratory studies exist on the impact of external tagging on eels, with PSATs in particular [10-12]. Interestingly however, no significant effect was observed on the eel's optimal swimming speed when equipped with a PSAT. In contrast, the minimum cost of transport increased significantly by a minimum $26 \%[10,12]$. In the natural environment no difference in migration speed was observed by Righton et al. [4] using different tag types (PSAT, PDST, DST and acoustic transmitters), both internally implanted and externally attached, but the energy consumption could not be studied as the eels were not recaptured.

Apart from an impact on swimming performance, external tagging may also influence eel behaviour. Laboratory studies have described various types of reactions by eels such as head shaking, biting the tag, rolling, backward swimming, panicking burst speeds and even using the tail to try to remove the tag [13]. In addition, general insights to the post-release movement behaviour in eels are still lacking, such as the potential recovery time at the release site or their departure direction. Potentially eels may be more affected by external tags compared to pelagic fish species since eels tend to hide between crevices and bury in the bottom substrate [14].
In the present study, we tested the hypothesis that departure direction, time spent at the release location and migration ground speed do not differ between eels equipped with both external PDSTs and internal tags and eels tagged only with internal tags. We implanted 66 migrating eels with acoustic transmitters of which half got an additional externally attached PDST and tracked their behaviour using strategically placed acoustic receivers at the release site, and at key migration routes from the Baltic Sea to the North Sea.

\section{Results}

The median residence time at the release site of the 28 eels tagged with PDSTs was $4.2 \mathrm{~h}$ and did not differ significantly from the median residence time of the 32 eels not tagged with PDSTs $(5.0 \mathrm{~h}$; Mann-Whitney $U$ test, $W=526, p=0.25$ ) (Fig. 1). The direction at which the eels left the release site did not differ significantly neither between the two groups (Mann-Whitney $U$ test, $W=447, p=0.38$ ) (Fig. 2). Sixteen eels (nine PDST tagged and seven without PDSTs) were only detected on the receivers closest to land during their departure, suggesting that these eels had moved very close to shore as they left the release site. The median migration speed between the 13 eels tagged with PDSTs and the seven without did not differ significantly (Mann-Whitney $U$ test, $W=53, p=0.59): 4.4$ vs. $8.8 \mathrm{~km} \mathrm{day}^{-1}$, respectively (Fig. 3).

\section{Discussion}

In this study, we investigated the impact of externally attached PDSTs on the migration behaviour of the European eel in the Baltic Sea. Our results show that eels tagged with PDSTs exhibit a similar residence time after release as eels without PDSTs. Also the direction in which both groups left the release site was similar. These results indicate that the impact of the external PDST is minimal in terms of the recovery behaviour briefly after the tagging procedure. In contrast, a longer stay at the release site upon surgery and handling has been observed with other fish species [15]. For some fish species it is known they rub their skin against surfaces or the substrate to remove skin irritation, a phenomenon known as chafing [16]. Since we did not observe the fish under water, we cannot draw conclusions on this aspect. However, the external tagging method we used, i.e. the Westerberg method, is considered relatively less invasive and showed a minimum of behavioural responses in the laboratory [13].

Our results also suggest that at least during the first ca. $83 \mathrm{~km}$ after tagging, the migration speed of the eels tagged with external PDSTs is not significantly different than eels without PDSTs. This is in line with the results 


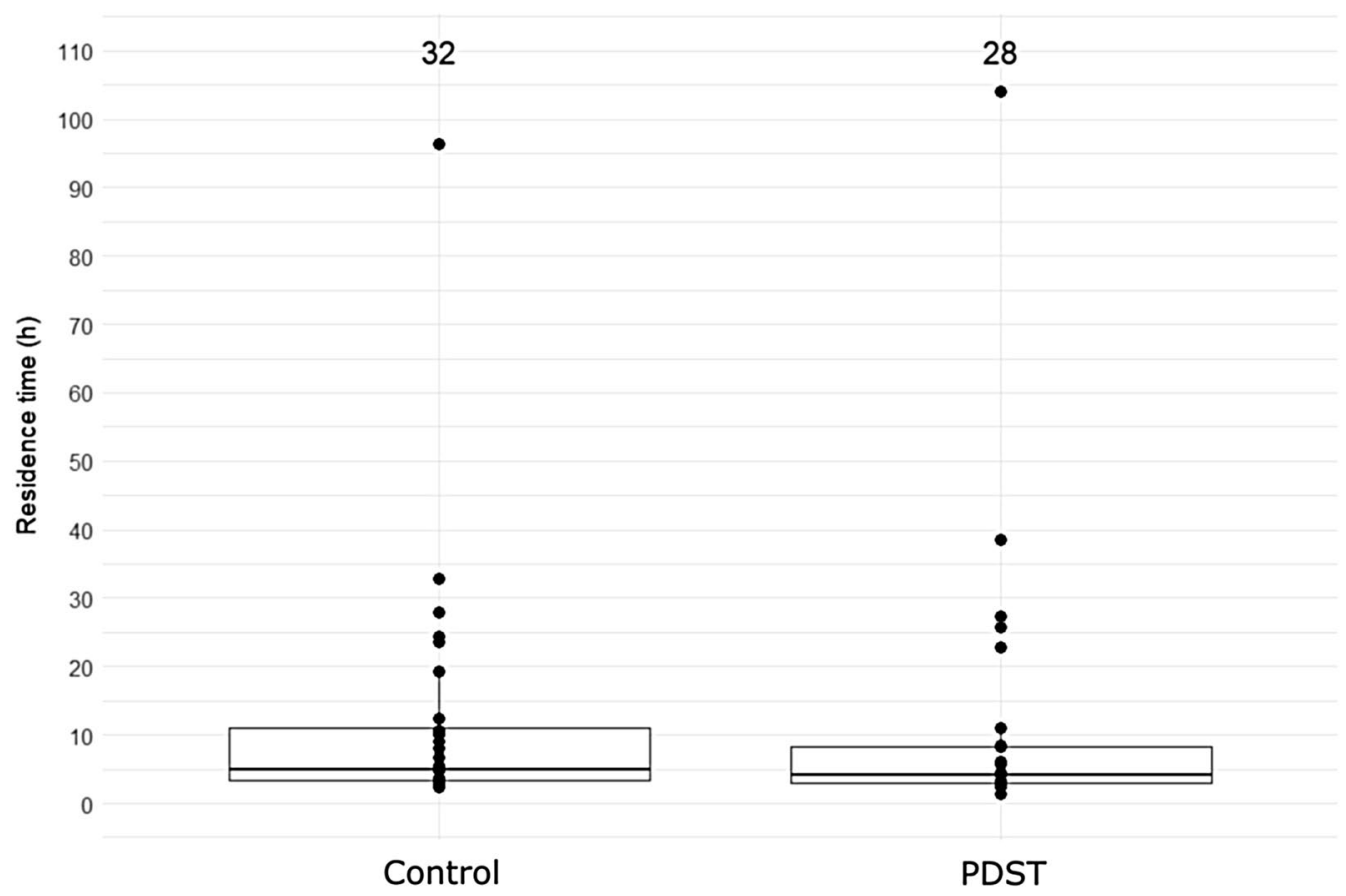

Fig. 1 The residence time (hours) between eels tagged without (control) and with PDSTs. The data points are represented as dots in the boxplot. The number of eels in each group is indicated at the top of the boxplot

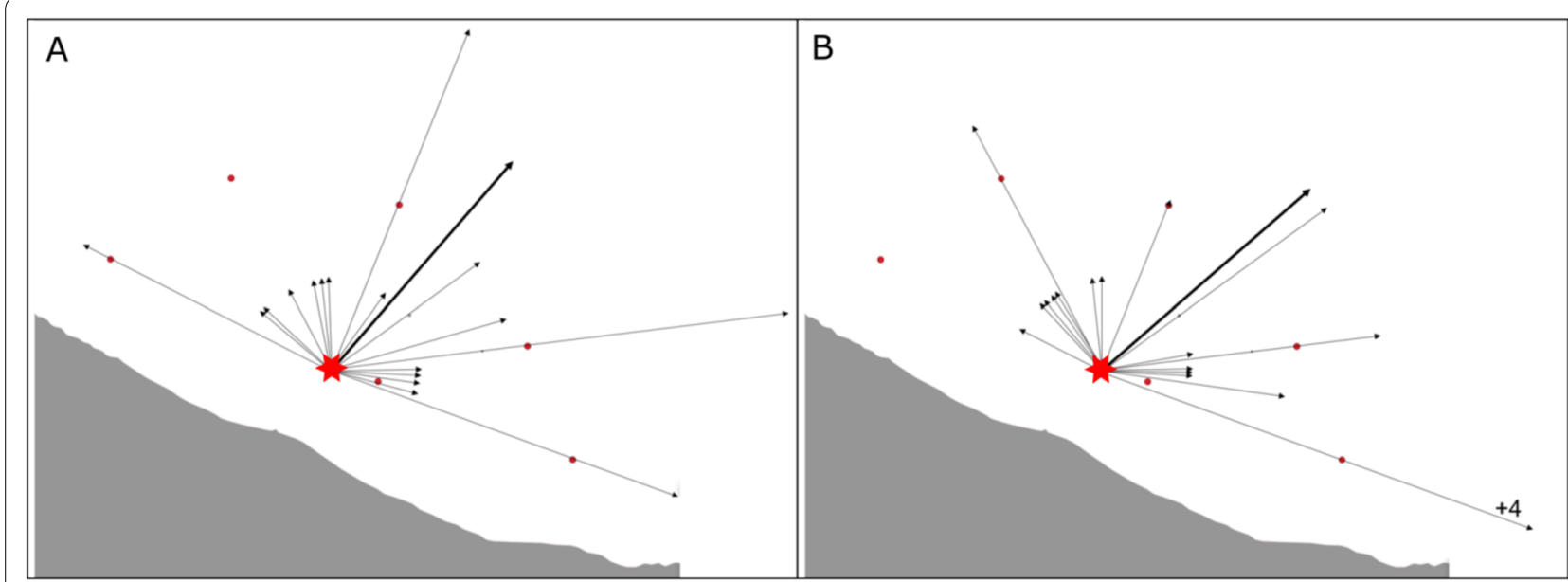

Fig. 2 The departure vectors of released eels without (A) and with (B) PDSTs at the release site. The thicker black vector represents the mean departure angle for the given group. The individual departure angles are represented as grey arrows of which the length represents the number of individuals. Receiver positions are indicated with red circles and the release location with a red star

obtained by Righton et al. [4] who found no significant difference in speed between eels tagged with various tag types, such as acoustic, PSATs and both internal and external attached DSTs. We do acknowledge that the median migration speed of the eels tagged with PDSTs is only half of those without, yet large variability in speed was similar between both groups. In addition, due to technical challenges of mooring receivers at the Danish Straits, data were lost, resulting in the detection of only $43 \%$ of the acoustically tagged eels and hence a small sample size. Obviously, our results rely on the assumption that the external PDSTs stayed on the eels at least until their detection at the receiver array of The Sound. It took the eels between 3 to 91 days to reach that array. 


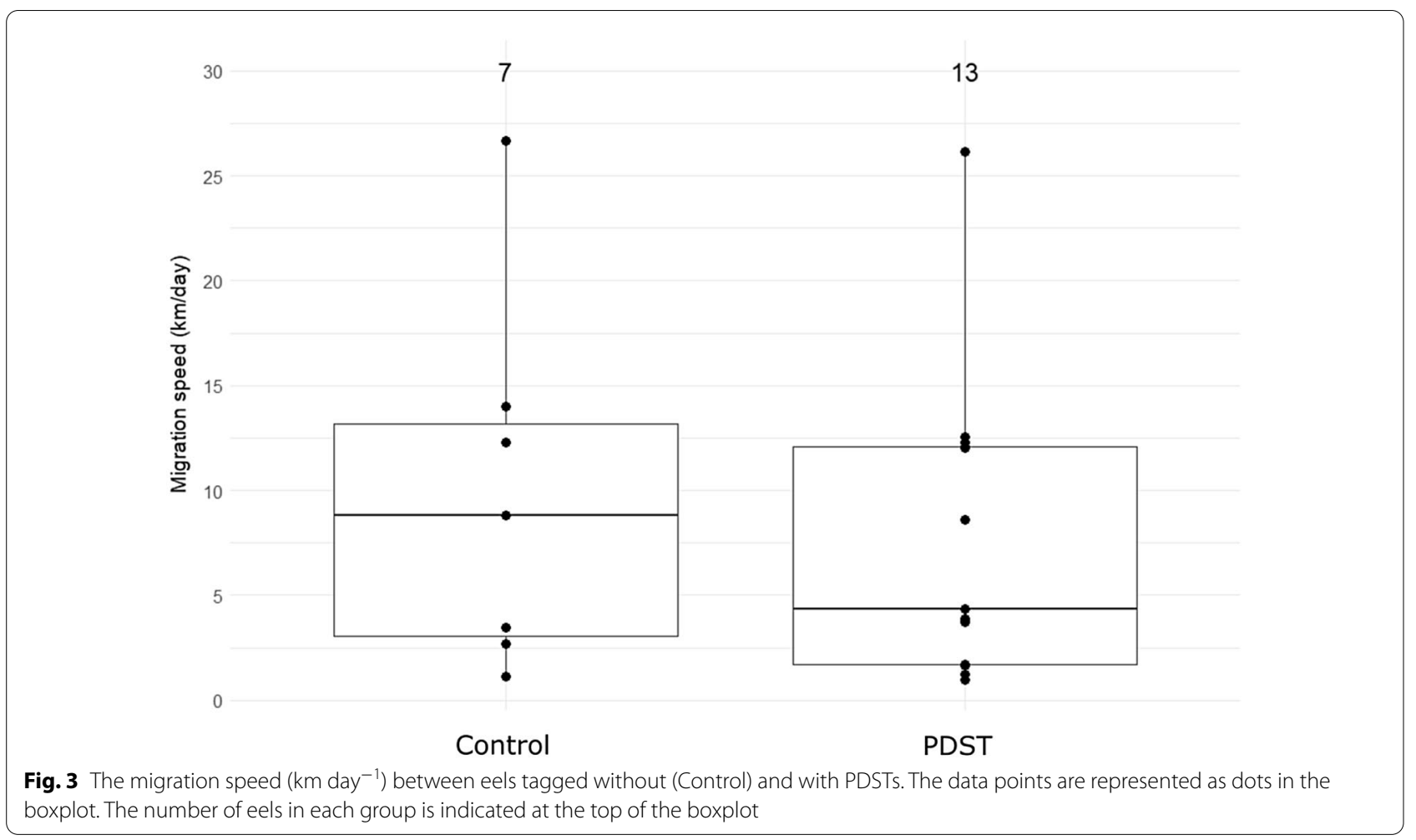

Eleven of the PDSTs that were retrieved indicated an average $\pm S D$ (premature) pop-off time after $95 \pm 73$ (2-202) days (Additional file 1: Table S1). Of these, three were tagged with an acoustic transmitter of which two had their PDST during detection on the arrays between the Danish Isles and Sweden (179 and 183 days at large). The third lost its PDST after 19 days and was not detected on the arrays. Further, according to a laboratory study on six eels tagged with the Westerberg attachment method, no tags came off during that period, not even when those eels were introduced to a tank with structural features which could enhance tag loss [13].

Nonetheless, we only studied the first $83 \mathrm{~km}$ of the eel's migration route. As the total route is more than $7000 \mathrm{~km}$, it could be that detrimental PDST effects manifest themselves further at sea, for instance by slowing down due to exhaustion by the extra drag. Also, even though the effect on migration speed seems negligible, it might be that the energy consumption increased and swimming efficiency decreased to account for the extra drag by the PDSTs [12]. Although these effects have been studied under laboratory conditions for PSATs [11, 12, 17], the effects by much smaller and differently shaped PDSTs are yet to be studied. Even more, we highly recommend to mimic at least some of the ambient conditions the eels experience in the wild, such as water temperature and pressure. For instance, in laboratory conditions the water temperature is often much higher (e.g. $18{ }^{\circ} \mathrm{C}$ ) compared to the environmental conditions the eels experience during their migration in autumn and winter at sea $\left(\mathrm{ca} .10^{\circ} \mathrm{C}\right)[10$, $11,17]$. Water temperature plays a pivotal role in ectothermic fish like anguillid eels, influencing fish ecology, physiology and behaviour [18]. Sockeye salmon (Oncorhynchus nerka) that migrated at higher water temperatures suffered from a disrupted ionoregulatory system leading to physiological stress [19]. Also, higher temperatures can stimulate infections and disease development $[20,21]$, making especially the wounds of the tag-attachment more vulnerable. Another, yet difficult parameter to control is the pressure. Eels migrate at depths between 200 and over $800 \mathrm{~m}$ in the ocean [6,22]. It is very likely that such depth differences have a substantial effect on the eels swimming performance and energy consumption as well, but it is unclear to what degree. Also, many laboratory studies use eels which are smaller than those tagged in the wild. The eels in our study had an average total length of $867 \pm 51 \mathrm{~mm}$ and weighed $1338 \pm 189 \mathrm{~g}$, which is in line with other archival tracking studies on European eel [4]. The sizes in laboratory conditions are in some cases not even half these sizes [12, 17]. Although in these studies a scaled-down PSAT replica was used, we argue that it would be a better practice to use the real devices to draw more reliable conclusions on effects in the wild. Further, some studies use farmed eels instead of 
wild silver eels, which may also influence the results $[10$, 17].

Finally, PDSTs have a positive buoyancy which could affect the vertical movement behaviour of eels. It would therefore be relevant for future research to compare this vertical movement behaviour between eels tagged with and without PDSTs. Although we used depth sensors on the acoustic transmitters for 2019's batch, we could not perform such an analysis due to a limited dataset: detections occurred at only two locations, being the release site and one of the arrays between the Danish Isles and Sweden. Also, the depth sensor values of the 2019's InnovaSea Systems Inc. transmitters could not be picked up by the Thelma Biotel receivers in the arrays arguing for a better compatibility between acoustic telemetry brands [23].

\section{Conclusion}

PDSTs are an effective tool to study the marine spawning migration behaviour of the European eel. Nonetheless, the increasing application of archival tags on anguillid eels to map their spawning migration routes and locations $[4,5,8,24]$ demands research on the potential effects of such devices on the eel's migration behaviour. Despite previous research in the laboratory on the swimming performance and energetics of eels carrying a PSAT, it is important to test for potential effects in the natural environment as well. Laboratory studies have used controlled environments, which lack the variability of the ambient environment to which migrating eels are exposed. Logically, it is difficult to mimic such a dynamic environment in a laboratory, and the goal is often to reduce ambient variability as much as possible. Nonetheless, taking into account or even studying specific environmental variables in relation to the impact of the external tag to the eels' swimming performance can aid interpretation of the data obtained in the wild. Also, the majority of the laboratory studies focus on PSATS, hence, there is an urgent need to run tests on the impacts of the much smaller PDSTs on eel swimming performance. The outcome of such studies would not only help interpret the data obtained from field studies, but also aid the development of more hydrodynamic tag shapes or even better tag-attachment methods to reduce the impact on the eel swimming stamina.

\section{Materials and methods Study area}

Fish tagging and tracking took place in seas surrounding eastern Denmark, located at the transition area between the North Sea and the Baltic Sea. This marine area is relatively shallow $(0-50 \mathrm{~m})$ with sea surface salinity increasing gradually over a distance of roughly $300 \mathrm{~km}$ from 6 to
10 PSU in the Baltic to 35 PSU in the North Sea. A permanent halocline stratifies the water in the region with brackish water from the Baltic flowing on top of heavier, more saline North Sea waters. The Baltic Sea has three outlets, the Danish Straits: one between the Jutland Peninsula and the island of Funen (The Little Belt, $0.7 \mathrm{~km}$ wide), one between the islands Funen and Zealand (The Great Belt, $16.2 \mathrm{~km}$ wide) and one between the island of Zealand and the Swedish mainland (The Sound, $3.9 \mathrm{~km}$ wide) (Fig. 4).

\section{Capture and tagging of eels}

Capture, tagging and release of the eels took place in Eastern Denmark, located on the Southern side of the receiver lines (Fig. 4). Eels were caught by a commercial eel fisherman using pound nets with 200-400 m long leaders deployed perpendicularly to the coast. The roughly 50 square metre pounds were emptied between 7 and 9 a.m. in the morning and the eels were transferred directly from the pound to a live well on the fishing boat. Eels were fetched from the live well in batches of 5-10 and stored in an oxygenated 50-L container prior to sedation and tagging. In total, 66 eels $\left(n_{2019}=38\right.$ and $\left.n_{2020}=28\right)$ were anaesthetized with benzocaine (300 ppm) until they lost equilibrium (5-8 min). We measured the total length (to the nearest $\mathrm{mm}$ ) and weight (to the nearest g), and identified the eels in the silvering stage based on external characteristics: silver-coloured abdomen, dark grey on the dorsal side, jaw hinge not proceeding beyond the eye, enlarged eyes and dark coloured pectoral fins. The eels measured on average $867 \pm 51 \mathrm{~mm}$ (range: $743-$ $980 \mathrm{~mm}$ ) total length and weighed $1338 \pm 189 \mathrm{~g}$ (range: 1003-1857 g). Only females were tagged, since males are smaller than the minimum size handled in this study $(<450 \mathrm{~mm}$ [25]). Acoustic transmitters with a diameter of $9 \mathrm{~mm}$ were surgically implanted in the abdominal cavity, after which the incision was closed with three non-soluble monofilament sutures. In 2019, V9P ID transmitters with pressure sensor from InnovaSea Systems Inc. were used, measuring $31 \mathrm{~mm}$ in length, $9 \mathrm{~mm}$ in diameter and weighing $4.9 \mathrm{~g}$ in air and $2.8 \mathrm{~g}$ in water. In 2020, ID-MP9 ID transmitters from Thelma Biotel were used, measuring $24 \mathrm{~mm}$ in length, $9 \mathrm{~mm}$ in diameter and weighing $3.6 \mathrm{~g}$ in air and $2.1 \mathrm{~g}$ in water. Every second eel was also tagged externally with a PDST (G5 PDST, CEFAS Technology Ltd, UK) following the subcutaneous three-point Westerberg attachment method [13]: three stainless steel mono wires $(0.6 \mathrm{~mm})$ were threaded subcutaneously through the skin in front of the dorsal fin. These three wires were threaded through the three loops of the PDST attachment and subsequently closed with a stainless steel sleeve of $1.5 \mathrm{~mm}$. These PDSTs measure $61 \mathrm{~mm}$ in length, $30 \mathrm{~mm}$ in diameter, weighing $32 \mathrm{~g}$ in air and $-0.1 \mathrm{~g}$ in 


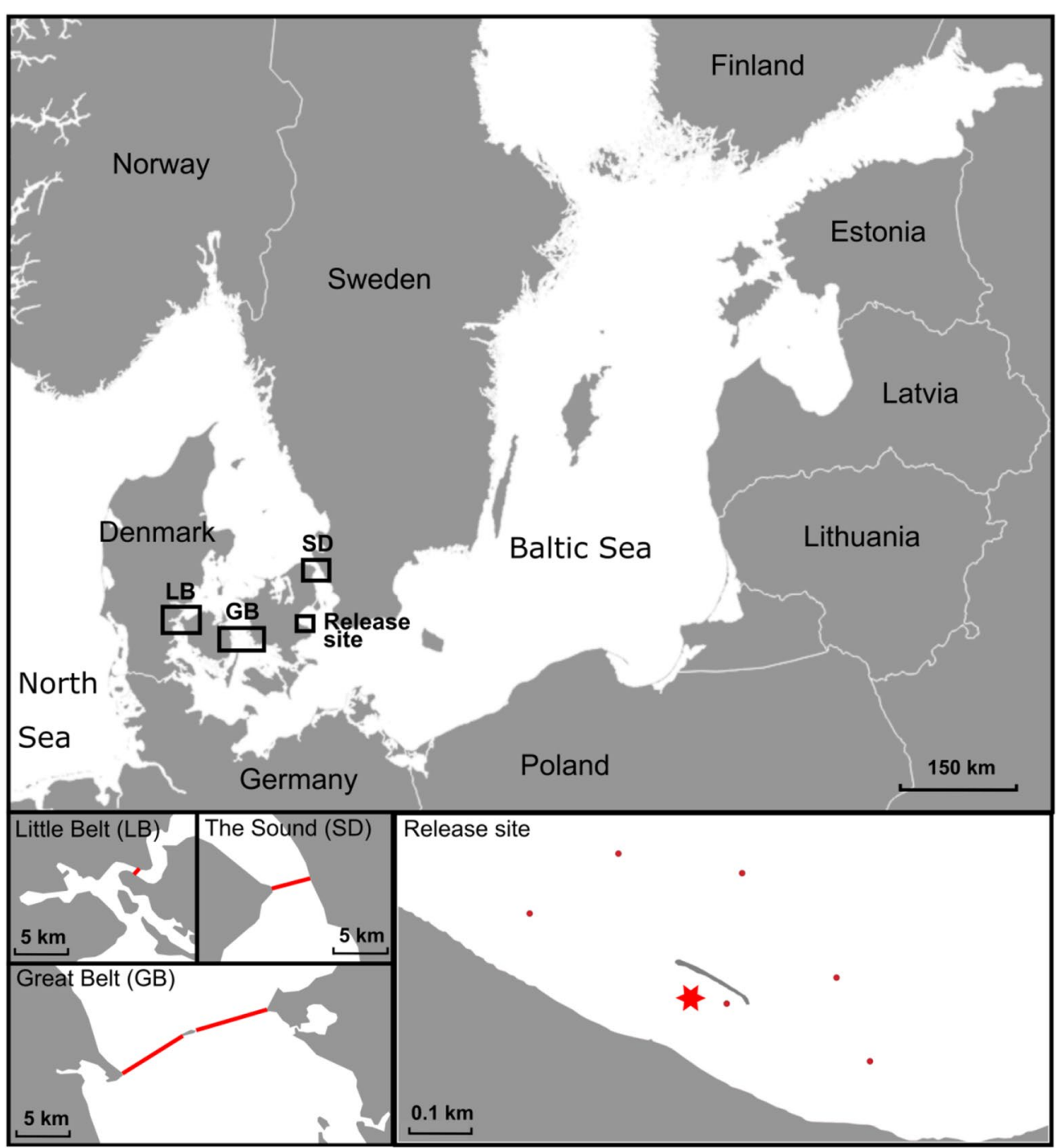

Fig. 4 Map of the study area with the receiver lines in the Little Belt, Great Belt and Sound marked with red lines; land is in grey. The release location is marked with a red star while the single receiver at the release location and the five receivers around the release location are marked with red circles

seawater. The PDSTs were programmed to pop-off after 6 months. Upon recovery from the surgery in a water tank, the eels were released near a wave breaker.

\section{Acoustic network}

In 2019, a network of acoustic receivers (InnovaSea VR2W and VR2AR, and Thelma Biotel TBR700L) was deployed between the Danish Isles and Sweden: the Little Belt contains six receivers, the Great Belt 34 and the Sound 8-14 receivers. Thirty-four receivers were moored directly onto bridges or other existing constructions 3-4 $\mathrm{m}$ below surface level, while units with a release mechanism were deployed on the seabed with a $35 \mathrm{~kg}$ anchor. Receiver spacing was $160-550 \mathrm{~m}$ to detect as many acoustically tagged animals as possible when crossing the lines. This was generally achieved in the Sound, where a single receiver placed $1000 \mathrm{~m}$ upstream from the receiver line during the first year of the study detected a total of 16 acoustic tags (from this and other studies) of which 15 had subsequently been detected on the line. This transect was additionally upgraded from a single line with eight receivers during the first year of the study to a double line with six and eight receivers, respectively, during the second year. The Great Belt was problematic during the first year of the present study, in which a total of 12 receivers were lost in a series of severe storms during 
the migration period of the eels, resulting in data loss. Minimum swimming distance from the release site to the receiver lines were $83 \mathrm{~km}$ to The Sound, $146 \mathrm{~km}$ to the Great Belt and $285 \mathrm{~km}$ to the Little Belt. The locations of the receiver lines are presented on Fig. 4.

At the release site, one receiver was deployed near the exact release location, while five receivers were evenly spaced $(250-400 \mathrm{~m})$ in an arch around that location. These six receivers were deployed on the seabed with an anchor and marked using a surface buoy. Data from the receivers were downloaded two to three times per year.

\section{Data analysis}

Of the 66 tagged eels, six were recaptured (five with PDST) in 2019 near the release location by a commercial eel fisherman. Although two were released again, we decided to remove all six eels from further analysis as recapture could compromise our results and interpretation. Tagging in 2020 took place on the last night of the fishing season, so no eels were recaptured this year.

For the remaining 60 eels, the impact of PDSTs on the post-release behaviour was studied by calculating the residence time at the release location for each eel, being the time between release and the last detection on one of the six receivers at the release location. A non-parametric one-sided Mann-Whitney-Wilcoxon $U$ test was applied to statistically determine a difference in median residence time between eels tagged with and without PDSTs. This non-parametric test was chosen since the data did not follow a normal distribution (Shapiro test, $W=0.50$, $p<0.001$ ), yet the assumption of homogeneity of variances was met ( $F$-test, $F=0.29, p=0.74$ ).

The estimated departure directions from the release site were obtained to observe the post-release behaviour of eels in general and to check for potential differences between eels with or without PDSTs. An average position was calculated from detections in the final $5 \mathrm{~min}$ a given eel had resided within the range of the release site receivers, following the position average method according to Simpfendorfer et al. [26]. The idea of using this method rather than simply looking at the final receiver an eel was detected at, was to account for eels moving out between receivers and thus provide a better, though still rough, estimate of departure direction from the release site for both eel groups. The final averaged position in the release site area was translated into an estimated departure angle with reference to the point of release using

$$
\text { Departureangle }=\tan ^{-1}\left(\frac{\text { Difference in UTM northing }}{\text { Difference in UTM easting }}\right) .
$$

Next, a non-parametric one-sided Mann-WhitneyWilcoxon $U$ test was applied to statistically determine a difference in median departure direction between eels tagged with and without PDSTs. This non-parametric test was chosen since the data did not follow a normal distribution (Shapiro test, $W=0.88, p<0.001$ ), yet the assumption of homogeneity of variances was met ( $F$-test, $F=0.93, p=0.85$ ).

We calculated the migration ground speed as the distance between the release location and the detection at the furthest receiver outside of the release site (i.e. at a receiver of the Little Belt, Great Belt or the Sound) divided by the migration time. Eels not detected in the Little Belt, Great Belt or Sound were excluded from this part of the analysis. Hence, of the 60 eels, 26 eels were detected on the different receiver arrays during their migration to the North Sea: 20 (13 with PDST) passed the Sound, five (one with PDST) the Great Belt and one (none with PDST) the Little Belt. This resulted in an unbalanced design between the different routes and limited data on the routes other than the Sound Hence, since the majority of the eels (77\%) migrated through the Sound, we analysed the migration speed of this group only. We applied a non-parametric one-sided Mann-Whitney-Wilcoxon $U$ test to analyse if the median migration speed differed significantly between eels tagged with PDSTs and without. This non-parametric approach was applied since the data did not follow a normal distribution (Shapiro test, $W=0.84, p=0.003)$. The variances were homogenously distributed ( $F$-test, $F=1.06, p=0.51)$. All analyses were performed in R [27].

\section{Supplementary Information}

The online version contains supplementary material available at https://doi. org/10.1186/s40317-022-00280-4.

Additional file 1:Table S1. This table shows the IDs of the eleven retrieved PDSTs and whether or not the eels had an internally implanted acoustic transmitter. The release and pop-off date time is indicated, as well as the time the tag was attached to the eel.

\section{Acknowledgements}

We want to thank Jørgen Pedersen who provided us field infrastructure and food and drinks to increase our stamina during the cold and dark days of eel tagging. We also want to thank the commercial fishermen John Ring Nielsen and his co-workers from the company John's Fisk for providing us the live eels we needed for our study.

\section{Authors' contributions}

PV and MLK conceived the idea, performed the analyses and wrote the manuscript. PV, MLK and KA tagged the eels, and MLK, GH and NS downloaded data from the receivers. GH, NJ, AK, JR, NS and JCS all contributed with equipment and arranged the funds for the study. All authors assisted in writing, read and approved the final manuscript.

\section{Funding}

This work makes use of data and infrastructure provided by VLIZ and INBO, which is funded by the Research Foundation Flanders (FWO) as part of the Belgian contribution to LifeWatch. Funding for acoustic tags, deployment and maintenance of the receiver infrastructure was provided by The European Maritime and Fisheries Fund (EMFF) and The Danish rod and net fishing license funds. The Ocean Tracking Network (OTN), the Technical University of 
Denmark, the Norwegian Institute of Marine Resources and the Swedish University of Agricultural Sciences provided the acoustic receivers for the project. In Sweden, these receivers were financed by the Swedish Agency for Marine and Water Management SwAM (Dnr 1230-20) within the project ÅLAKUT at the Swedish University of Agricultural Sciences.

\section{Availability of data and materials}

The datasets used and analyed during the current study are available from the corresponding author on request.

\section{Declarations}

\section{Ethics approval and consent to participate}

The study was performed under permission number 2017-15-0201-01164 from the Danish experimental animal welfare board.

\section{Consent for publication}

Not applicable.

\section{Competing interests}

The authors declare that they have no competing interests.

\begin{abstract}
Author details
'Aquatic Management, Research Institute for Nature and Forest (INBO), Havenlaan 88, Bus 73, 1000 Brussels, Belgium. ${ }^{2}$ Marine Biology Research Group, Ghent University, Krijgslaan 281, 9000 Ghent, Belgium. ${ }^{3}$ Technical University of Denmark, National Institute for Aquatic Resources, 8600 Silkeborg, Denmark. ${ }^{4}$ Department of Aquatic Resources (SLU Aqua), Swedish University of Agricultural Sciences, Stångholmsvägen 2, 17893 Drottningholm, Sweden. ${ }^{5}$ Flanders Marine Institute (VLIZ), Wandelaarkaai 7, 8400 Ostend, Belgium.
\end{abstract}

Received: 27 November 2021 Accepted: 17 February 2022

Published online: 04 March 2022

\section{References}

1. Hussey NE, Kessel ST, Aarestrup K, Cooke SJ, Cowley PD, Fisk AT, Harcourt RG, Holland KN, Iverson SJ, Kocik JF. Aquatic animal telemetry: a panoramic window into the underwater world. Science. 2015;348:1255642.

2. Pedersen MW, Righton D, Thygesen UH, Andersen KH, Madsen H. Geolocation of North Sea cod (Gadus morhua) using hidden Markov models and behavioural switching. Can J Fish Aquat Sci. 2008;65:2367-77.

3. Wright SR, Lynam CP, Righton DA, Metcalfe J, Hunter E, Riley A, Garcia L, Posen $\mathrm{P}$, Hyder K. Structure in a sea of sand: fish abundance in relation to man-made structures in the North Sea. ICES J Mar Sci. 2020:77:1206-18.

4. Righton D, Westerberg H, Feunteun E, Økland F, Gargan P, Amilhat E, Metcalfe J, Lobon-Cervia J, Sjöberg N, Simon J. Empirical observations of the spawning migration of European eels: the long and dangerous road to the Sargasso Sea. Sci Adv. 2016;2: e1501694.

5. Béguer-Pon M, Castonguay M, Shan S, Benchetrit J, Dodson JJ. Direct observations of American eels migrating across the continental shelf to the Sargasso Sea. Nat Commun. 2015;6:8705

6. Schabetsberger R, Økland F, Aarestrup K, Kalfatak D, Sichrowsky U, Tambets M, Dall'Olmo G, Kaiser R, Miller PI. Oceanic migration behaviour of tropical Pacific eels from Vanuatu. Mar Ecol Prog Ser. 2013;475:177-90.

7. Jellyman D, Tsukamoto K. First use of archival transmitters to track migrating freshwater eels Anguilla dieffenbachii at sea. Mar Ecol Prog Ser. 2002:233:207-15

8. Westerberg H, Sjöberg N, Lagenfelt I, Aarestrup K, Righton D. Behaviour of stocked and naturally recruited European eels during migration. Mar Ecol Prog Ser. 2014:496:145-57.

9. Simon J, Westerberg H, Righton D, Sjöberg N, Dorow M. Diving activity of migrating silver eel with and without Anguillicola crassus infection. J Appl Ichthyol. 2018;34:659-68.

10. Burgerhout E, Manabe R, Brittijn SA, Aoyama J, Tsukamoto K, van den Thillart GE. Dramatic effect of pop-up satellite tags on eel swimming. Naturwissenschaften. 2011;98:631-4.

11. Tudorache C, Burgerhout E, Brittijn S, van den Thillart G. Comparison of swimming capacity and energetics of migratory European eel (Anguilla anguilla) and New Zealand short-finned eel (A. australis). Front Physiol. 2015;6:256.

12. Methling C, Tudorache C, Skov PV, Steffensen JF. Pop up satellite tags impair swimming performance and energetics of the European eel (Anguilla anguilla). PLoS ONE. 2011;6: e20797.

13. Økland F, Thorstad EB, Westerberg H, Aarestrup K, Metcalfe JD. Development and testing of attachment methods for pop-up satellite archival transmitters in European eel. Anim Biotelem. 2013;1:3.

14. Steendam C, Verhelst P, Van Wassenbergh S, De Meyer J. Burrowing behaviour of the European eel (Anguilla anguilla): Effects of life stage. J Fish Biol. 2020;97:1332-42.

15. Chateau O, Wantiez L. Post-release activity of three coral reef fish species in a marine reserve: analysis and recommendations for telemetry studies. Environ Biol Fish. 2021;104:15-26.

16. Wyman RL, Walters-Wyman MF. Chafing in fishes: occurrence, ontogeny, function and evolution. Environ Biol Fish. 1985:12:281-9.

17. Tudorache C, Burgerhout E, Brittijn S, Van den Thillart G. The effect of drag and attachment site of external tags on swimming eels: experimental quantification and evaluation tool. PLoS ONE. 2014. https://doi.org/10. 1371/journal.pone.0112280.

18. Fry F. The effect of environmental factors on the physiology of fish. In: Hoar WS, Randall DJ (Eds.) Fish physiology, vol 1. New York: Academic Press; 1971. pp. 1-98.

19. Cooke SJ, Hinch SG, Crossin GT, Patterson DA, English KK, Shrimpton JM, Kraak GVD, Farrell AP. Physiology of individual late-run Fraser River sockeye salmon (Oncorhynchus nerka) sampled in the ocean correlates with fate during spawning migration. Can J Fish Aquat Sci. 2006;63:1469-80.

20. Gilhousen P. Prespawning mortalities of sockeye salmon in the Fraser River system and possible causal factors. International Pacific Salmon Fisheries Commission; 1992.

21. Wagner G, Hinch S, Kuchel L, Lotto A, Jones SR, Patterson D, Macdonald J, Kraak GVD, Shrimpton M, English K. Metabolic rates and swimming performance of adult Fraser River sockeye salmon (Oncorhynchus nerka) after a controlled infection with Parvicapsula minibicornis. Can J Fish Aquat Sci. 2005:62:2124-33.

22. Aarestrup K, Økland F, Hansen MM, Righton D, Gargan P, Castonguay M, Bernatchez L, Howey P, Sparholt H, Pedersen MI. Oceanic spawning migration of the European eel (Anguilla anguilla). Science. 2009;325:1660-1660.

23. Reubens J, Aarestrup K, Meyer C, Moore A, Okland F, Afonso P. Compatibility in acoustic telemetry. Anim Biotelem. 2021;9:1-6.

24 Schabetsberger R, Scheck A, Kaiser R, Leaana R, Gubili C, Økland F. Oceanic migration behaviour of Pacific eels from Samoa. Fish Manag Ecol. 2018. https://doi.org/10.1111/fme.12298.

25. Durif C, Dufour S, Elie P. The silvering process of Anguilla anguilla: a new classification from the yellow resident to the silver migrating stage. J Fish Biol. 2005;66:1025-43.

26. Simpfendorfer CA, Heupel MR, Hueter RE. Estimation of short-term centers of activity from an array of omnidirectional hydrophones and its use in studying animal movements. Can J Fish Aquat Sci. 2002;59:23-32.

27. R Core Team. R: a language and environment for statistical computing (version 4.0.3). R Foundation for Statistical Computing, Vienna, Austria. http://wwwR-project.org. 2020.

\section{Publisher's Note}

Springer Nature remains neutral with regard to jurisdictional claims in published maps and institutional affiliations. 